University of Nebraska - Lincoln

DigitalCommons@University of Nebraska - Lincoln

Faculty Publications: Department of

Entomology

Entomology, Department of

1999

\title{
Virulence of Metarhizium anisopliae (Deuteromycotina: Hyphomycetes) Strain ESC-1 to the German Cockroach (Dictyoptera: Blattellidae) and Its Compatibility with Insecticides
}

\author{
Pari Pachamuthu \\ University of Nebraska-Lincoln \\ Shripat T. Kamble \\ Universitiy of Nebraska--Lincoln, skamble1@unl.edu \\ Gary Y. Yuen \\ University of Nebraska-Lincoln, gyuen1@unl.edu
}

Follow this and additional works at: https://digitalcommons.unl.edu/entomologyfacpub

Part of the Entomology Commons

Pachamuthu, Pari; Kamble, Shripat T.; and Yuen, Gary Y., "Virulence of Metarhizium anisopliae (Deuteromycotina: Hyphomycetes) Strain ESC-1 to the German Cockroach (Dictyoptera: Blattellidae) and Its Compatibility with Insecticides" (1999). Faculty Publications: Department of Entomology. 311.

https://digitalcommons.unl.edu/entomologyfacpub/311

This Article is brought to you for free and open access by the Entomology, Department of at DigitalCommons@University of Nebraska - Lincoln. It has been accepted for inclusion in Faculty Publications: Department of Entomology by an authorized administrator of DigitalCommons@University of Nebraska - Lincoln. 


\title{
Virulence of Metarhizium anisopliae (Deuteromycotina: Hyphomycetes) Strain ESC-1 to the German Cockroach (Dictyoptera: Blattellidae) and Its Compatibility with Insecticides
}

\author{
PARI PACHAMUTHU,${ }^{1}$ SHRIPAT T. KAMBLE,${ }^{1,2}$ AND GARY Y. YUEN ${ }^{3}$
}

\begin{abstract}
J. Econ. Entomol. 92(2): 340-346 (1999)
ABSTRACT Virulence of Metarhizium anisopliae (Metschnikoff) Sorokin strain ESC-1 against the German cockroach, Blattella germanica (L.), was determined using 5 concentrations ranging from $8 \times 10^{7}$ to $2 \times 10^{9}$ spores per milliliter. The calculated $L_{50}$ value was 4.18 by $10^{8}$ spores per milliliter $\left(4.18 \times 10^{5}\right.$ spores per cockroach). In vitro study was conducted to determine the compatibility of M. anisopliae strain ESC-1 with chlorpyrifos, propetamphos, and cyfluthrin. Insecticides did not affect conidial germination but did adversely affect the growth and sporulation of M. anisopliae strain ESC-1. The growth of M. anisopliae colonies on media amended only with 50 and $500 \mathrm{ppm}$ of chlorpyrifos and $500 \mathrm{ppm}$ of propetamphos treatments at 3,6 , and $9 \mathrm{~d}$ was significantly inhibited compared with the control. Similarly, sporulation was significantly reduced in treated colonies exhibiting partial colony growth. The colonies cultured on SDAY media amended with $50 \mathrm{ppm}$ of chlorpyrifos had significantly reduced sporulation compared with the control and no sporulation was observed in colonies cultured on media amended with $500 \mathrm{ppm}$ of chlorpyrifos and propetamphos.
\end{abstract}

KEY WORDS Metarhizium anisopliae, Blattella germanica, virulence, insecticide compatibility, germination, sporulation

ThE ENTOMOPathogenic Fungus Metarhizium anisopliae (Metschnikoff) Sorokin has been isolated from at least 200 insect species and is a potential candidate for microbial control. Each of the isolates differs significantly in its pathogenicity against a target species; therefore, a potential pathogen must be evaluated individually against a target insect pest (Zimmermann 1993). Different strains of M. anisopliae have been used for controlling many agriculturally important insect pests such as beetles (Liu et al. 1989, Moorhouse et al. 1993), aphids (Milner and Soper 1981), planthoppers (Samuels et al. 1989), and pear psylla (Puterka et al. 1994). The use of this fungus as a potential control agent in the household environment also was evaluated against termites (Kramm et al. 1982) and ants (Kelley-Tunis et al. 1995).

Despite considerable research on the use of Metarhizium sp. for crop insect control, there are very few reports on the application of this fungus to control the German cockroach, Blattella germanica (L). Metarhizium anisopliae strain ESC-1 was formulated commercially as Bio-Path for controlling cockroaches by Ecoscience, but it was discontinued because of inconsistent mortality. Kaakeh et al. $(1996,1997)$ reported lethal time of M. anisopliae to German cockroaches but not the lethal concentrations. Moreover, Kaakeh et al. (1996) included mortality data based on

\footnotetext{
${ }^{1}$ Department of Entomology, University of Nebraska, Lincoln, NE 68583-0816.

${ }^{2}$ To whom correspondence should be addressed.

${ }^{3}$ Department of Plant Pathology, University of Nebraska, Lincoln, NE 68583-0816.
}

contact assay and there was no documentation of total number of M. anisopliae spores required to cause mortality in German cockroaches. Bio-Path, the commercial product of M. anisopliae strain ESC-1, required $28 \mathrm{~d}$ for $85 \%$ mortality (Kaakeh et al. 1996; Kamble and Prabhakaran, unpublished data). Although M. anisopliae has the potential to be an effective agent, the extended time required to control cockroaches has been the most important factor in the failure of BioPath. Therefore, there is a critical need to enhance the biological activity of $M$. anisopliae by integrating it with sublethal doses of conventional insecticides leading to an integrated pest management (IPM) approach.

Efficacy of the fungus Beauveria bassiana (Balsamo) Vuillemin was improved by combining it with sublethal doses of insecticides (Ferron 1971, Anderson et al. 1989). B. bassiana was found to be compatible with abamectin and triflumuron (Anderson et al. 1989) but incompatible with diflubenzuron, carbaryl, methomyl, and methyl parathion (Gardner et al. 1979). The integration of any fungal isolate with an insecticide requires a thorough knowledge of the compatibility between the two agents (Gardner et al. 1979, Vanninen and Hokkanen 1988), particularly the percentage of spore germination, growth, and sporulation. Based on colony growth and percentage of germination, many entomopathogenic fungal strains were found to be compatible with insecticides, including phosphamidon (Urs et al. 1967), permethrin (Clark et al. 1982), diazinon, cypermethrin (Vanninen and Hokkanen 1988, Moorhouse et al. 1992), carbofuran ( $\mathrm{Li}$ and Hol- 
dom 1994), aldicarb (Samuels et al. 1989, Li and Holdom 1994), and pirimicarb (Vanninen and Hokkanen 1988). In contrast, BHC (Urs et al. 1967), azinphosmethyl, carbofuran (Clark et al. 1882), chlorpyrifos (Samuels et al. 1989, Li and Holdom 1994), ethoprophos, and fenamiphos (Li and Holdom 1994) inhibited the growth of entomopathogenic fungal strains.

Another indicator of compatibility between a fungus and insecticide is fungal sporulation ( $\mathrm{Li}$ and Holdom 1994). Sporulation can be affected by pesticides (Gardner and Storey 1985) and a potential inhibitory effect of pesticides can affect the epizootic condition of the disease or reduce the efficacy of the strains in the field. In most of the compatibility studies, sporulation of the fungus was affected by insecticide concentrations (Urs et al. 1967, Gardner et al. 1979, Samuels et al. 1989).

Although in vitro compatibility studies between entomopathogens and insecticides have been conducted for agricultural pests, such research concept has not been thoroughly evaluated to control German cockroaches in urban settings. This concept is not new, yet the data on lethal concentrations of M. anisopliae and the effect of insecticides on conidial germination, mycelial growth, and sporulation of $M$. anisopliae are essential components in developing an effective IPM program for controlling German cockroaches. In vitro research on combination of fungi and insecticides will provide viable baseline information on their compatibility before conducting in vivo studies. Furthermore, the integration of biological agents with sublethal concentrations of insecticides will reduce environmental contamination and improve human safety. We are hypothesizing that in vitro compatibility studies will enable us to select the insecticide doses that will enhance the effect of M. anisopliae and also will reduce the amount of insecticide used in the in vivo studies. This research was undertaken to evaluate the virulence of M. anisopliae strain ESC-1 against German cockroaches, to determine the lethal dose required to kill $50 \%$ of the target population, and to assess compatibility of $M$. anisopliae with commercially used insecticides at acceptable concentrations by the in vitro procedure.

\section{Materials and Methods}

Insects. The Chemical Specialities and Manufacture's Association (CSMA) strain of German cockroach is a insecticide-susceptible strain used as the target insect. The German cockroaches were reared on Purina dog chow (Ralston Purina, St. Louis, MO) and water, and maintained in Plexiglas containers (59 by 24 by $24 \mathrm{~cm}$ ). The cockroaches were reared at $27 \pm$ $2^{\circ} \mathrm{C}, 60 \pm 10 \% \mathrm{RH}$, and a photoperiod of 12:12 (L:D) h.

Conidial Production. The M. anisopliae strain ESC-1 was obtained from EcoScience, East Brunswick, NJ. The conidia were produced on Sabouraud dextrose agar yeast (SDAY) media (Moorhouse et al. 1992). This medium was prepared by mixing $1 \%$ (wt:vol) peptone, $1 \%$ (wt:vol) yeast, $4 \%$ (wt:vol) glucose, and $1.6 \%$ (wt:vol) agar (Difco, Detroit, MI) in distilled water. After autoclaving at $121^{\circ} \mathrm{C}$ for $20 \mathrm{~min}, \approx 16 \mathrm{ml}$ of media was poured into sterile petri dishes ( 10 by 1.5 $\mathrm{cm}$ ). Ten microliter of the spore solution, prepared in $0.05 \%$ Triton X-100, was placed in the center of each petri dish containing the media and sealed with parafilm. Spore cultures in sealed petri dishes were incubated at constant temperature $\left(27 \pm 2^{\circ} \mathrm{C}\right)$ in the dark for $21 \mathrm{~d}$. Conidia were harvested in sterile water containing $0.05 \%$ Triton X-100. Conidia from each plate were scraped with a sterile spatula, and the spore solution was filtered through an 8-layered cheese cloth (Style 280, Chicopee Mills, NY), centrifuged $\left(3,500 \times \mathrm{g}\right.$ for $15 \mathrm{~min}$ at $\left.4{ }^{\circ} \mathrm{C}\right)$, and resuspended in sterile water containing $0.05 \%$ Triton $\mathrm{X}-100$. The spore concentration was determined using a Neubauer hemocytometer. Spore concentration was determined by using the formula (total number of spores from both sides divided by $\left.2 \times\left[0.1 \mathrm{~mm}^{3}\right]\right) \times\left(1 \times 10^{3} \mathrm{~mm}^{3}\right.$ per milliliter), where $0.1 \mathrm{~mm}^{3}$ is the height and 1 by $10^{3} \mathrm{~mm}^{3}$ is the total area of the hemocytometer.

Topical Application with M. anisopliae. Based on the results of the preliminary experiment, 5 spore concentrations $\left(8 \times 10^{7}, 1.5 \times 10^{8}, 5 \times 10^{8}, 8.5 \times 10^{8}\right.$, and $2 \times 10^{9}$ spores per milliliter) and a control (treated with $1 \mu \mathrm{l}$ of $0.05 \%$ Triton X-100) were used for the subsequent bioassay. The required spore concentrations were measured from the stock solution and $1 \mu \mathrm{l}$ of the spore suspension was applied topically on the 1st ventral abdominal segment of each adult male German cockroach by using a Hamilton microliter syringe (Reno, NV). The treated cockroaches were placed in the Plexiglas container ( 15 by $6 \mathrm{~cm}$ ) (1 container per replication) and incubated at $27 \pm 2^{\circ} \mathrm{C}$ and $\approx 85 \% \mathrm{RH}$. Relative humidity within each container was monitored by placing the probe of the digital hygrometer and thermometer (Fisher, St. Louis, MO) inside the container and sealing it with masking tape. Mortality was observed daily for $21 \mathrm{~d}$, and dead cockroaches were removed daily. Moistened Whatman No. 1 filter paper $(18.5 \mathrm{~cm})$ was placed in each container to maintain high humidity $(\approx 85 \%)$. Food, water, and filter paper were changed every $3 \mathrm{~d}$. Each treatment was replicated 4 times with 10 adult male cockroaches per treatment, and the entire experiment was repeated twice. The mortality data were pooled and analyzed by probit analysis using the POLO program (Robertson and Preisler 1992), which provided both the chi-square and $t$-test values.

In Vitro Study on Compatibility of Insecticide with M. anisopliae. Commercial formulations of propetamphos (Safrotin, 18.9\% [AI], Sandoz Agro, Des Plaines, IL), chlorpyrifos (Dursban Pro, 23.5\% [AI], Dow Agroscience, Indianapolis, IN), and cyfluthrin (Tempo, $24.3 \%$ [AI], Bayer, KS, City, MO) were used in this study. The manufacturer's label recommended rates were 5,000 ppm (AI) for chlorpyrifos and propetamphos, and $500 \mathrm{ppm}$ (AI) for cyfluthrin for German cockroach control. We used the concentrations (sublethal doses) of $0.5,5,50$, and $500 \mathrm{ppm}$ (AI) for chlorpyrifos and propetamphos, and $0.05,0.5,5$, and $50 \mathrm{ppm}$ (AI) for cyfluthrin. The desired insecticide concentrations were prepared by serial dilution of the com- 
mercial formulation in distilled water. Because the insecticides used are emulsifiable concentrates (EC), the emulsifiers will enable the technical grade material to disperse in the water uniformly to form a suspension.

The SDAY medium was prepared as described under conidial production with slight modifications that consisted of adding dextrose solution (sterilized through a Nalgene reusable filter system by using a $0.22-\mu \mathrm{m}$ filter membrane (Fisher, St. Louis, MO) to the autoclaved media containing peptone, yeast, and agar. When the media cooled sufficiently, different concentrations of propetamphos, chlorpyrifos, and cyfluthrin were added ( $60 \mathrm{ml}$ of insecticide solution was added to $540 \mathrm{ml}$ of media [1:9 ratio]). In the SDAYamended insecticide media, dextrose, yeast, agar and peptone are in solution, whereas insecticides are in suspension. The bottles containing the insecticideamended SDAY media were then hand-shaken and rolled on the clean bench for $3 \mathrm{~min}$ to ensure the uniform mixing of insecticide with the media. Approximately $16 \mathrm{ml}$ of media amended with insecticides was poured into each petri dish and allowed to solidify at room temperature under the table top horizontal Laminar flow (Envirco, Jefferson, NM). Ten microliters of suspension of conidia in sterile distilled water containing $0.05 \%$ Triton $\mathrm{X}-100$ was placed in the center of plate, which was then sealed with parafilm and incubated in the dark at $27 \pm 2^{\circ} \mathrm{C}$.

Conidial Germination, Colony Diameter, and Sporulation. Conidial germination was determined $12 \mathrm{~h}$ later by observing the spores for germ tube development. The diameter of each culture was measured on 3,6, and $9 \mathrm{~d}$ after incubation. Length and width of colony growth were measured for each culture, and the averages of these values were used to express the colony growth per plate. After $14 \mathrm{~d}$, the culture plates were stored at $4^{\circ} \mathrm{C}$ until conidial collection. Subsequently, conidia from each culture plate were collected by washing them in $50 \mathrm{ml}$ of $0.05 \%$ Triton X-100. The colony was initially washed with 20 $\mathrm{ml}$ of $0.05 \%$ Triton $\mathrm{X}-100$, and $15 \mathrm{ml}$ of the solution was used in the ensuing 2 washes. The spore solutions were then centrifuged, resuspended in $0.05 \%$ Triton X-100, and the final concentration determined usingthe Neubauer hemocytometer.

Experimental Design. The experimental design for determining the effect of insecticide on germination, colony growth, and sporulation was a randomized complete block design with 8 replications per treatment. Conidial germination and sporulation data were transformed by arcsin and log transformation procedures, respectively. Data were analyzed by PROC GLM (SAS Institute 1990). The values were compared by least significant difference (LSD) tested by using PROC GLM.

\section{Results}

Virulence of M. anisopliae Strain ESC-1. The cockroach mortality observed in the initial experiment was 16,20 , and $90 \%$ when exposed to M. anisopliae spores

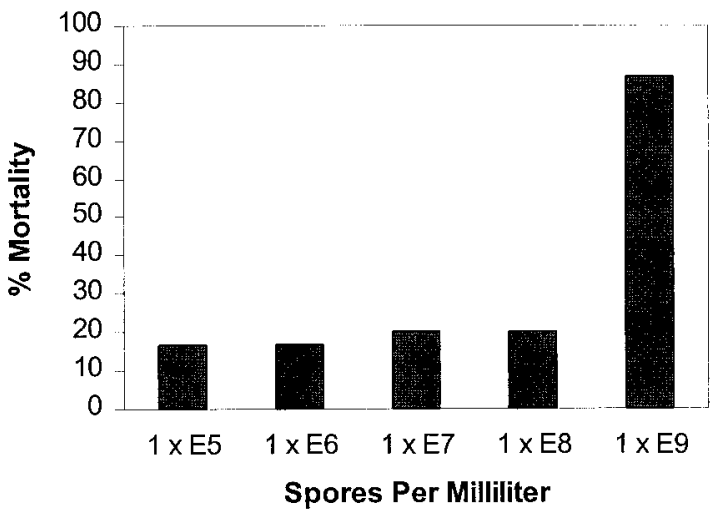

Fig. 1. Mortality caused by M. anisopliae strain ESC-1 to CSMA strain of German cockroach. E, exponential.

(Fig. 1). Based on initial mortality data, the concentrations from $8 \times 10^{7}$ to $2 \times 10^{9}$ spores per milliliter were selected for the subsequent 2 bioassays. The average cockroach mortality ranged from 31 to $86 \%$ in the treated populations, whereas $16 \%$ mortality was observed in the untreated cockroaches (Table 1). The $\mathrm{LD}_{50}$ value obtained was $4.18 \times 10^{8}$ spores per milliliter $\left(4.18 \times 10^{5}\right.$ spores per cockroach $)$ with a upper limit of $6.34 \times 10^{8}$ spores per milliliter $\left(6.34 \times 10^{5}\right.$ spores per cockroach) and a lower limit of $2.73 \times 10^{8}$ spores per milliliter $\left(2.73 \times 10^{5}\right.$ spores per cockroach $)$ (99\% CI). The $t$-ratio was 6.85 and the $\chi^{2}$ value was 1.68. Fig. 2a indicates the conidia at the time of incubation, whereas Fig. 2b illustrates the germinated conidia bearing the germ tube (if the length of the germ tube was at least half the length of the spore, the conidia was considered to have germinated). The percentage of germination of M. anisopliae spores used in the initial experiment was $91 \%$, whereas the percentages of conidial germination used in 1st and 2nd bioassays were 92 and $93 \%$, respectively.

Effect of Insecticides on Spore Germination. The $M$. anisopliae strain ESC-1 did not exhibit any significant difference $(P>0.05)$ in the conidial germination resulting from incorporation of insecticides into the SDAY media (Table 2). The conidial germination of M. anisopliae strain ESC-1 cultured on media incorporated with insecticides (chlorpyrifos, propetamphos, and cyfluthrin) was 96 or $97 \%$.

Effect of Insecticides on Fungal Colony Growth. There were significant differences in growth of $M$.

Table 1. Mortality (mean \pm SEM) in CSMA strain of German cockroach caused by $M$. anisopliae strain ESC-1

\begin{tabular}{lll}
\hline \hline Spore concn/ml & $n^{a}$ & \% mortality \\
\hline $8.0 \times 10^{7}$ & 80 & $31.3 \pm 1.8$ \\
$1.5 \times 10^{8}$ & 80 & $32.5 \pm 7.1$ \\
$5.0 \times 10^{8}$ & 80 & $62.5 \pm 10.6$ \\
$8.5 \times 10^{8}$ & 80 & $76.5 \pm 8.8$ \\
$2.0 \times 10^{9}$ & 80 & $86.3 \pm 1.8$ \\
Control & 80 & $16.3 \pm 1.8$ \\
\hline
\end{tabular}

${ }^{a}$ Number of male German cockroaches used for each concentration. 

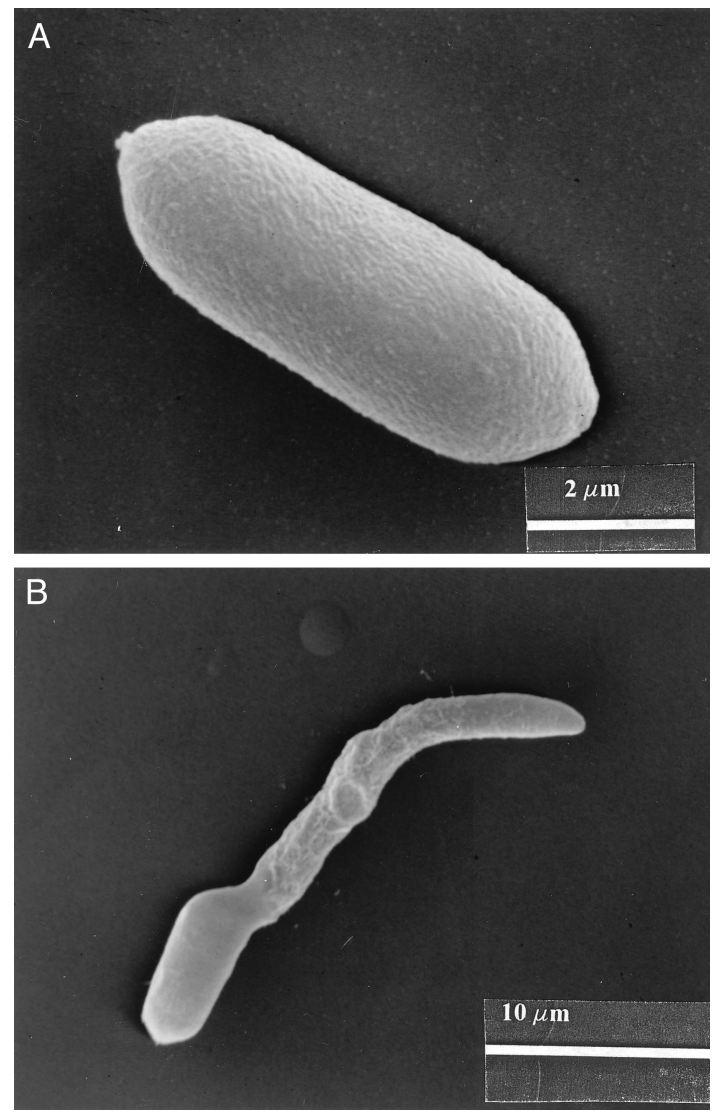

Fig. 2. (a) Scanning electron micrograph of M. anisopliae conidia strain $(14,000 \times)$ cultured on SDAY media at time zero. (b) Germ tube development $(3,800 \times)$ after $12 \mathrm{~h}$ of incubation at $27 \pm 2^{\circ} \mathrm{C}$.

anisopliae cultured on media amended with chlorpyrifos (50 and $500 \mathrm{ppm})$ and propetamphos (500 ppm) compared with the control (Table 3). The diameter of

Table 2. Conidial germination (mean \pm SEM) of M. anisopliae strain ESC-1 cultured on SDAY media amended with selected insecticides

\begin{tabular}{lcc}
\hline $\begin{array}{c}\text { SDAY media }+ \text { insecticides } \\
(\mathrm{ppm})\end{array}$ & \% germination & $\begin{array}{c}\text { Arcsin-transformed } \\
\text { values }^{a}\end{array}$ \\
\hline Chlorpyrifos (0.5) & $96.13 \pm 0.99$ & $1.37 \mathrm{a}$ \\
Chlorpyrifos (5) & $96.50 \pm 2.07$ & $1.39 \mathrm{a}$ \\
Chlorpyrifos (50) & $97.13 \pm 1.46$ & $1.41 \mathrm{a}$ \\
Chlorpyrifos (500) & $96.75 \pm 1.36$ & $1.40 \mathrm{a}$ \\
Propetamphos (0.5) & $95.87 \pm 2.23$ & $1.37 \mathrm{a}$ \\
Propetamphos (5) & $96.50 \pm 1.41$ & $1.39 \mathrm{a}$ \\
Propetamphos (50) & $97.00 \pm 2.00$ & $1.41 \mathrm{a}$ \\
Propetamphos (500) & $96.00 \pm 1.31$ & $1.37 \mathrm{a}$ \\
Cyfluthrin (0.05) & $97.13 \pm 1.46$ & $1.41 \mathrm{a}$ \\
Cyfluthrin (0.5) & $97.13 \pm 1.46$ & $1.41 \mathrm{a}$ \\
Cyfluthrin (5) & $97.00 \pm 2.07$ & $1.41 \mathrm{a}$ \\
Cyfluthrin (50) & $96.63 \pm 1.30$ & $1.39 \mathrm{a}$ \\
Control & $97.00 \pm 1.41$ & $1.41 \mathrm{a}$ \\
\hline
\end{tabular}

${ }^{a}$ Transformed values followed by same letter are not significantly different by Fisher LSD $(P>0.05)$. Values under each column are means of 8 replicate plates. LSD conidial germination, 0.05 .
Table 3. Diameter (mean \pm SEM) of M. anisopliae strain ESC-1 cultured on insecticide-amended SDAY media

\begin{tabular}{llll}
\hline \hline $\begin{array}{c}\text { SDAY media }+ \\
\text { insecticides (ppm) }\end{array}$ & \multicolumn{1}{c}{ Day 3 } & Day 6 & Day 9 \\
\hline Chlorpyrifos (0.5) & $21.8 \pm 1.2 \mathrm{a}$ & $39.0 \pm 2.5 \mathrm{a}$ & $54.9 \pm 1.6 \mathrm{ab}$ \\
Chlorpyrifos (5) & $21.5 \pm 1.5 \mathrm{abc}$ & $39.3 \pm 2.6 \mathrm{ab}$ & $55.5 \pm 1.6 \mathrm{a}$ \\
Chlorpyrifos (50) & $17.1 \pm 0.4 \mathrm{~d}$ & $31.4 \pm 0.7 \mathrm{~d}$ & $45.5 \pm 1.9 \mathrm{e}$ \\
Chlorpyrifos (500) & $16.3 \pm 0.7 \mathrm{e}$ & $28.6 \pm 1.7 \mathrm{e}$ & $39.7 \pm 1.2 \mathrm{f}$ \\
Propetamphos (0.5) & $21.5 \pm 1.3 \mathrm{abc}$ & $38.8 \pm 2.6 \mathrm{ab}$ & $54.7 \pm 2.1 \mathrm{ab}$ \\
Propetamphos (5) & $21.7 \pm 1.4 \mathrm{ab}$ & $38.9 \pm 2.3 \mathrm{ab}$ & $54.0 \pm 1.8 \mathrm{bcd}$ \\
Propetamphos (50) & $21.0 \pm 1.1 \mathrm{c}$ & $38.1 \mathrm{~b} \pm 2.3 \mathrm{c}$ & $52.7 \pm 1.3 \mathrm{~d}$ \\
Propetamphos (500) & $16.1 \pm 1.5 \mathrm{e}$ & $26.2 \pm 1.5 \mathrm{f}$ & $35.3 \pm 1.9 \mathrm{~g}$ \\
Cyfluthrin (0.05) & $21.7 \pm 1.5 \mathrm{ab}$ & $38.6 \pm 2.5 \mathrm{ab}$ & $54.3 \pm 1.9 \mathrm{abc}$ \\
Cyfluthrin (0.5) & $21.5 \pm 1.7 \mathrm{abc}$ & $38.6 \pm 3.1 \mathrm{ab}$ & $54.0 \pm 2.6 \mathrm{bcd}$ \\
Cyfluthrin (5) & $21.5 \pm 1.4 \mathrm{abc}$ & $38.3 \pm 3.1 \mathrm{bc}$ & $54.1 \pm 2.4 \mathrm{bcd}$ \\
Cyfluthrin (50) & $21.2 \pm 1.5 \mathrm{abc}$ & $38.7 \pm 2.5 \mathrm{ab}$ & $54.3 \pm 2.4 \mathrm{abc}$ \\
Control & $21.3 \pm 1.3 \mathrm{bc}$ & $37.6 \pm 2.7 \mathrm{c}$ & $53.1 \pm 2.1 \mathrm{~cd}$ \\
\hline
\end{tabular}

Means followed by same letter are not significantly different by Fisher LSD test $(P>0.05)$. Values under each column are means of 8 replicate plates. LSD of 3-d growth, 0.62; LSD 6-d growth, 0.91; LSD 9-d growth, 1.46.

the colonies observed on 3,6 , and $9 \mathrm{~d}$ was as follows: $16.3,28.6$, and $39.7 \mathrm{~mm}$ for chlorpyrifos at $500 \mathrm{ppm}$; $17.1,31.4$, and $45.5 \mathrm{~mm}$ for chlorpyrifos at $50 \mathrm{ppm}$; and $16.1,26.2$, and $35.3 \mathrm{~mm}$ for propetamphos at $500 \mathrm{ppm}$, respectively. Growth of M. anisopliae cultured on media amended with 0.5 and 5 ppm of chlorpyrifos was higher than on the control. On day 3, the growth of $M$. anisopliae was statistically similar among colonies cultured on media amended with $0.5 \mathrm{ppm}$ and $5 \mathrm{ppm}$ of chlorpyrifos and the control. The colony diameters in these 2 treatments, however, were significantly larger than the control on day 6 and 9 .

Metarhizium anisopliae cultured on propetamphosamended SDAY media had the same growth patterns compared with the control colonies except for the colonies raised on propetamphos 500 ppm-amended media (Table 3). There was no significant difference in the growth of $M$. anisopliae cultured on media amended with $0.5,5$, and $50 \mathrm{ppm}$ of propetamphos on day 3. M. anisopliae colonies cultured on media amended with 0.5 and $5 \mathrm{ppm}$ of propetamphos, however, were significantly larger than the control colonies on day 6 . There was no difference between the control and $50 \mathrm{ppm}$ of propetamphos. On day 9 , there was no significant difference between the colony diameter in the control compared with 5 and $50 \mathrm{ppm}$ of propetamphos, but the colony diameter in media amended with $0.5 \mathrm{ppm}$ of propetamphos was significantly larger than in the control.

Unlike the growth pattern observed on SDAY media amended with chlorpyrifos and propetamphos, cyfluthrin-amended media did not exhibit any inhibitory effect on the growth of M. anisopliae cultures (Table 3 ). On days 3 and 9 , there was no significant difference in growth of the M. anisopliae cultured on SDAY media amended with $0.05,0.5,5$, and 50 ppm of cyfluthrin and the control. The growth of M. anisoplaie cultured in media amended with 5 ppm of cyfluthrin was statistically similar to the control on day 6. M. anisopliae had better growth patterns on media amended with 0.05 , 
Table 4. Sporulation of M. anisopliae strain ESC-1 cultured on insecticide-amended SDAY media after $14 \mathrm{~d}$

\begin{tabular}{lcc}
\hline \hline $\begin{array}{c}\text { SDAY media }+ \\
\text { insecticides (ppm) }\end{array}$ & $\begin{array}{c}\text { Spore } \\
\text { concn } \pm \\
\text { SEM }^{a}\end{array}$ & $\begin{array}{c}\text { Log } \\
\text { transformed } \\
\text { values }^{b}\end{array}$ \\
\hline Chlorpyrifos (0.5) & $1.17 \pm 0.24$ & $20.86 \mathrm{bcde}$ \\
Chlorpyrifos (5) & $1.40 \pm 0.29$ & $21.04 \mathrm{abc}$ \\
Chlorpyrifos (50) & $0.36 \pm 0.14$ & $19.62 \mathrm{f}$ \\
Chlorpyrifos (500) & $0.00 \pm 0.00$ & $0.00 \mathrm{~g}$ \\
Propetamphos (0.5) & $1.21 \pm 0.27$ & $20.89 \mathrm{bcde}$ \\
Propetamphos (5) & $1.38 \pm 0.24$ & $21.06 \mathrm{ab}$ \\
Propetamphos (50) & $1.20 \pm 0.14$ & $21.01 \mathrm{abc}$ \\
Propetamphos (500) & $0.00 \pm 0.00$ & $0.00 \mathrm{~g}$ \\
Cyfluthrin (0.05) & $1.07 \pm 0.27$ & $20.76 \mathrm{e}$ \\
Cyfluthrin (0.5) & $1.09 \pm 0.17$ & $20.79 \mathrm{de}$ \\
Cyfluthrin (5) & $1.16 \pm 0.38$ & $20.83 \mathrm{cde}$ \\
Cyfluthrin (50) & $1.41 \pm 0.49$ & $21.189 \mathrm{abcd}$ \\
Control & $1.60 \pm 0.25$ & \\
\hline
\end{tabular}

\footnotetext{
${ }^{a}$ Spore concentration is expressed in $10^{9}$ conidia per plate.

$b$ Transformed values followed by same letter are not significantly different by Fisher LSD $(P>0.05)$. Values under each column are means of 8 replicate plates. LSD sporulation, 0.21
}

0.5 , and $50 \mathrm{ppm}$ of cyfluthrin compared with the control.

Effect of Insecticides on Sporulation. There was a significant difference $(P<0.05)$ in the effect of sporulation in M. anisoplaie cultured on media amended with selected insecticides. The sporulation ranged from 0.00 to $1.6 \times 10^{9}$ spores per culture with the highest sporulation observed in the control, whereas the M. anisopliae cultured on $500 \mathrm{ppm}$ of chlorpyrifos and propetamphos-amended media did not sporulate (Table 4). The spore concentration of M. anisopliae cultured on media amended with $50 \mathrm{ppm}$ of chlorpyrifos was significantly lower than that of the other treatments. Only 4 treatments ( $5 \mathrm{ppm}$ of chlorpyrifos, 5 and $50 \mathrm{ppm}$ of propetamphos, and $50 \mathrm{ppm}$ of cyfluthrin) had sporulation concentrations that were similar to that of the control.

In chlorpyrifos-amended media, no significant differences were observed in the spore concentrations between M. anisoplaie cultured on 0.5 and $5 \mathrm{ppm}$ of chlorpyrifos, but the values were significantly different for colonies cultured on 50- and 500-ppm treatments. There were no significant differences in spore concentration of M. anisopliae cultured on $0.5,5$, and $50 \mathrm{ppm}$ of propetamphos. In cyfluthrin-amended media, there were significant differences in spore concentration between $0.05 \mathrm{ppm}$ and $50 \mathrm{ppm}$ of cyfluthrin, whereas the values were similar for treatments 0.5 , 5 , and $50 \mathrm{ppm}$ of cyfluthrin.

\section{Discussion}

We found that M. anisopliae strain ESC-1 caused appreciable high mortality in the susceptible CSMA strain of German cockroach at $21 \mathrm{~d}$ following treatment. Kamble and Prabhakaran (unpublished data) and Kaakeh et al. (1996) also reported a similar finding in the susceptible Orlando-N and JWax strains of German cockroach, where high mortality (85 and $100 \%$, respectively) was observed by a contact method after
$28 \mathrm{~d}$. Trends observed in our study are similar to the results of Kaakeh et al. (1996), where mortality caused by M. anisopliae strain ESC-1 increased with increased contact time between infected and uninfected German cockroach nymphs as well as the number of infected nymphs used with uninfected nymphs. Although low mortality at spore concentrations of $\leq 1.5 \times 10^{8}$ spores per milliliter was observed in our study, there was a linear relationship between the spore doses used and the mortality observed. These results were further substantiated by the chi-square value, which clearly indicated that the model fits the probit analysis. According to Liu et al. (1989), Puterka et al. (1994), and Jones et al. (1996), the virulence of any fungal isolate to cause mortality in insects is directly related to the spore concentration. Our data follow a similar pattern, in which mortality increased from 31.3 to $76.5 \%$, translating to a $40 \%$ increase in mortality for a 10 -fold increase in spore concentration. Based on our results, M. anisopliae strain ESC-1 with high viability ( $>90 \%$ germination) and a high spore concentration $\left(4.18 \times 10^{8}\right.$ spores per milliliter $\left[5 \times 10^{5}\right.$ spores per cockroach]) is needed for obtaining high mortality in German cockroaches at optimum conditions of $27^{\circ} \mathrm{C}$ and $\approx 85 \% \mathrm{RH}$. Our data indicate that $M$. anisopliae strain ESC-1can be an effective biopesticide for cockroach control after $21 \mathrm{~d}$; however, such a lengthy time becomes the most limiting factor. We agree with Kaakeh et al. (1996) that M. anisopliae can be used in an IPM system, further hypothesizing that the fungus can yield higher mortality if it is used in combination with sublethal doses of insecticides.

Growth and sporulation of $M$. anisopliae strain ESC-1 were more sensitive to insecticides than was the conidial germination. There was no significant difference in conidial germination of M. anisopliae strain ESC-1 on media amended with different concentrations of chlorpyrifos, propetamphos, and cyfluthrin. High germination of $M$. anisopliae strain observed after $12 \mathrm{~h}$ of incubation on media amended with insecticides could have been influenced by previous exposure of conidia to SDAY media, resulting in enough reserve nutrients (carbohydrates, lipids, and amino acids) (Hawker and Madelin 1976, Van Etten et al. 1983) to initiate the process of germ tube development when placed in a solid substrate containing exogenous nutrients (Dillon and Charnley 1990). St. Leger et al. (1989) also demonstrated that M. anisopliae conidia cultured in yeast extract medium (YEM) on polystyrene produced germ tubes within 7-12 $\mathrm{h}$ after incubation. Rapid germination of $M$. anisopliae could be attributed to metabolic activities that take place within a conidium by using reserve nutrients and a minimum amount of exogenous carbon source needed for germ tube formation after its placement on a substrate (Gottlieb 1976, Smith and Grula 1981, St. Leger et al. 1989). Al-Aidross and Seifert (1980) demonstrated that conidia of wild and mutant Metarhizium strains produced germ tubes in water agar and they attributed the early germination of some strains to carbohydrate metabolism. In contrast to the germ tube requirement, hyphae requires exogenous utilizable 
carbon and nitrogen for its growth (Smith and Grula 1981, St. Leger et al. 1989). Moorhouse et al. (1992) reported a similar pattern in which the majority of the pesticides did not affect conidial germination, except for zineb and chlorothalonil. Moorhouse et al. (1992) also reported that colony growth was affected by all pesticides except propamocarb. Therefore, germination alone should not be used as an indicator for predicting the compatibility between insecticide and entomopathogens. But high germination of an isolate implies its potential to be an effective agent under optimal conditions of temperature, relative humidity, and the presence of exogenous nutrient resources.

According to our results, colony growth was observed on media amended with all concentrations of insecticides, and there also was a significant difference in the growth pattern among insecticides. Growth of M. anisopliae strain ESC-1 was determined to be more sensitive to chlorpyrifos followed by propetamphos. Lack of inhibitory effect on colony growth caused by incorporation of cyfluthrin into SDAY media could be attributed to the highest concentration used, which was $1 / 10$ in comparison to chlorpyrifos and propetamphos treatments. Moorhouse et al. (1992) showed that partial inhibition of colony growth was caused by high concentrations of insecticides present in the SDAY media. Inhibition of M. anisopliae growth at high concentrations of chlorpyrifos also was documented by Samuels et al. (1989) and Li and Holdom (1994), but the growth and sporulation were compatible as insecticide concentration decreased. In our study, the growth and sporulation effect observed at $500 \mathrm{ppm}$ of chlorpyrifos and propetamphos is because of the formulated product. Thus, it is difficult to contemplate whether the inhibitory effect is caused by active ingredients or other inert ingredients. Our results on growth and sporulation are contrary to those of Vanninen and Hokkanen (1988), who stated that inhibition of mycelial growth does not necessarily mean that sporulation will be affected. We found that a $\approx 20 \%$ reduction in colony growth cultured on SDAY media incorporated with $500 \mathrm{ppm}$ of chlorpyrifos and propetamphos resulted in zero sporulation. The difference between these 2 studies could be the result of different compounds used in the study as well as to the method used for collecting spores. Vanninen and Hokkanen (1988) used a crude method of assessing the sporulation (i.e., spores were collected by placing a piece of tape on the colonies) instead of collecting all the spores from the plates.

There was no relationship between the insecticide concentration and sporulation as no increased sporulation due to decreased insecticide concentration was observed. Li and Holdom (1994) also reported a similar pattern where spore concentrations were not consistent between different treatments, and colonies cultured on high insecticide concentrations had better sporulation than the colonies cultured on low concentrations. The relationship between germination, growth, and sporulation indicates that factors affecting germination of M. anisopliae strain ESC-1 may be different from the ones affecting growth and sporu- lation in the presence of insecticides. Campbell et al. (1983) and Li and Holdom (1995) showed that uptake of carbohydrate and nitrogen from exogenous sources is essential for growth and sporulation of M. anisopliae. The SDAY-incorporated insecticide media used in our study had carbohydrate (dextrose) and nitrogen (peptone). Although the conidia are able to produce the germ tube, the presence of high concentrations of insecticide in the media seems to have an effect on growth and sporulation. The trend observed in our study also was reported by St. Leger et al. (1989), where germination was not affected but appressoria formation and hyphal differentiation were significantly affected by incorporation of certain macromolecule inhibitors into the nutrient media. Insecticide concentrations ranging from 0.1 to 10 times the recommended field rates have significant effects on growth and sporulation. Because there is a direct relationship between growth and insecticide concentration, this factor can impose a major limitation in the use of these 2 agents under laboratory or field conditions. If the concentration chosen is high (label recommended), the insecticide by itself can result in high mortality and lead to buildup of insecticide resistance faster or the insecticide present within the dead or infected insects might enhance or reduce the growth and sporulation of entomopathogens. Thus, in vitro studies can provide meaningful data that enable researchers to select the appropriate insecticide concentrations for conducting in vivo studies.

\section{Acknowledgments}

We thank Mischell Criag (University of Nebraska) for technical assistance in culturing and harvesting the fungal colonies, and Stephen Danielson and Steve Skoda (University of Nebraska) for their critical review of this article. This is published as Paper No. 12145, Journal Series, NE, Agricultural Division and Contribution No. 978, Department of Entomology, Institute of Agricultural and Natural Resources, University of Nebraska-Lincoln.

\section{References Cited}

AL-Aidross, K., and A. M. Seifert. 1980. Polysaccharide and protein degradation, germination, and virulence against mosquitoes in the entomopathogenic fungus Metarhizium anisopliae. J. Invertebr. Pathol. 36: 29-34.

Anderson, T. E., A. E. Hajek, D. W. Roberts, H. K. Preisler, and J. L. Robertson. 1989. Colorado potato beetle (Coleoptera: Chrysomelidae): effect of combinations of Beauveria bassiana with insecticides. J. Econ. Entomol. 82: 83-89.

Campbell, R. K., G. L. Barnes, B. O. Cartwright, and R. D. Eikenbary. 1983. Growth and sporulation of Beauveria bassiana and Metarhizium anisopliae in a basal medium containing various carbohydrate sources. J. Invertebr. Pathol. 41: 117-121.

Clark, R. A., R. A. Casagrande, and D. B. Wallace. 1982. Influence of pesticides on Beauveria bassiana, a pathogen of the Colorado potato beetle. Environ. Entomol. 11: $67-70$. 
Dillon, R. J., and A. K. Charnley. 1990. Initiation of germination in conidia of the entomopathogenic fungus, Metarhizium anisopliae. Mycol. Res. 94: 299-304.

Ferron, P. 1971. Modification of the development of Beauveria tenella mycosis in Melolontha melolontha larvae, by means of reduced doses of organophosphorus insecticides. Entomol. Exp. Appl. 14: 457-466.

Gardner, W. A., and G. K. Storey. 1985. Sensitivity of Beauveria bassiana to selected herbicides. J. Econ. Entomol. 78: 1275-1279.

Gardner, W. A., R. M. Sutton, and R. Noblet. 1979. Evaluation of the effects of six selected pesticides on the growth of Nomuraea rileyi and Beauveria bassiana in broth culture. J. Ga. Entomol. Soc. 14: 99-106.

Gottlieb, D. 1976. Carbohydrate metabolism and spore germination, pp. 141-164. In D. J. Weber and W. H. Hess [eds.], The fungal spore: form and function. Wiley, New York.

Hawker, L. E., and M. F. Madelin. 1976. The dormant spore, pp. 1-72. In D. J. Weber and W. H. Hess [eds.], the fungal spore: form and function. Wiley, New York.

Jones, W. E., J.E.K. Grace, and M. Tamashiro. 1996. Virulence of seven isolates of Beauveria bassiana and Metarhizium anisopliae to Coptotermes formosansus (Isoptera: Rhinotermitidae). Biol. Control 25: 481-487.

Kaakeh, W., B. L. Reid, T. J. Bohnert, and G. W. Bennett. 1996. Horizontal transmission of the entomopathogenic fungus Metarhizium anisopliae (Imperfect Fungi: Hyphomycetes) and hydramethylnon among German cockroaches (Dictyoptera: Blatellidae). J. Entomol. Sci. 31: 378-390.

1997. Toxicity of imidacloprid in the German cockroach (Dictyoptera: Blattellidae), and the synergism between imidacloprid and Metarhizium anisopliae (Imperfect Fungi. Hyphomycetes). J. Econ. Entomol. 90: 473-482.

Kelley-Tunis, K. K, B. L. Reid, and M. Andis. 1995. Activity of the entomopathogenic fungi in free-foraging workers of Camponotus pennsylvanicus (Hymenoptera: Formicidae). J. Econ. Entomol. 88: 937-943.

Kramm, K. R., D. F. West, and P. G. Rockenbach. 1982. Termite pathogens: transfer of the entomopathogen Metarhizium anisopliae between Reticulitermes sp. termites. J. Invertebr. Pathol. 40: 1-6.

Li, D. P., and D. G. Holdom. 1994. Effects of pesticides on growth and sporulation of Metarhizium anisopliae (Deuteromycotina: Hyphomycetes). J. Invertebr. Pathol. 63: 209-211.

1995. Effects of nutrients on colony formation, growth, and sporulation of Metarhizium anisopliae (Deuteromycotina: Hyphomycetes). J. Invertebr. Pathol. 65: 253-260.

Liu, S. D., S. C. Lin, and J. F. Shiau. 1989. Microbial control of coconut leaf beetle (Brontispa longissima) with green muscardine fungus, Metarhizium anisopliae var. anisopliae. J. Invertebr. Pathol. 53: 307-314.

Milner, R. J., and R. S. Soper. 1981. Bioassay of Entomophthora against the spotted alfalfa aphid, Therioaphis trifolii f. maculata. J. Invertebr. Pathol. 37: 168-173.

Moorhouse, E. R., A. T. Gillespie, E. K. Sellers, and A. K. Charnley. 1992. Influence of fungicides and insecticides on the entomogenous fungus Metarhizium anisopliae, a pathogen of the vine weevil, Otiorhynchus sulcaltus. Biocontrol Sci. Technol. 2: 49-58.

Moorhouse, E. R., A. T. Gillespie, and A. K. Charnley. 1993. Laboratory selection of Metarhizium spp. isolates for control of vine weevil larvae (Otiorhynchus sulcaltus). J. Invertebr. Pathol. 62: 15-21.

Puterka, G. J., R. A. Humber, and T. J. Poprawski. 1994. Virulence of fungal pathogens (Imperfecti Fungi: Hyphomycetes) to pear psylla (Homoptera: Psyllidae). Environ. Entomol. 23: 514-520.

Robertson, J. L., and H. K. Preisler. 1992. Pesticide bioassay with arthropods. CRC, Ann Arbor, MI.

Samuels, K.D.Z., J. B. Heale, and M. Llewellyn. 1989. Characteristics relating to the pathogenicity of Metarhizium anisopliae towards Nilaparvata lugens. J. Invertebr. Pathol. 53: 25-31.

SAS Institute. 1990. SAS/STAT user's guide, vols. 1 and 2. SAS Institute, Cary, NC.

St. Leger, R. J., T. M. Butt, M. S. Goettel, R. C. Staples, and D. W. Roberts. 1989. Production in vitro of appressoria by the entomopathogenic fungus Metarhizium anisopliae. Exp. Mycol. 13: 274-288.

Smith, R. J., and E. A. Grula. 1981. Nutritional requirements for conidial germination and hyphal growth of Beauveria bassiana. J. Invertebr. Pathol. 222-230.

Urs, N.V.R., H. C. Govindu, and K.S.S. Shastry. 1967. The effect of certain insecticides on the entomogenous fungi Beauveria bassiana and Metarhizium anisopliae. J. Invertebr. Pathol. 9: 398-403.

Van Etten, J. L., K. R. Dahlberg, and M. Geraldine. 1983. Fungal spore germination, pp. 235-268. In J. E. Smith [ed.], Fungal differentiation: a complementary synthesis. Marcel Dekker, New York.

Vanninen, I., and H. Hokkanen. 1988. Effect of pesticides on four species of entomopathogenic fungi in vitro. Ann. Agric. Fenn. 27: 347-353.

Zimmermann, G. 1993. The entomopathogenic fungus Metarhizium anisopliae and its potential as a biocontrol agent. Pestic. Sci. 37: 375-379.

Received for publication 17 September 1998; accepted 8 December 1998. 